\title{
Matrix metalloproteinases in the wound microenvironment: therapeutic perspectives
}

This article was published in the following Dove Press journal:

Chronic Wound Care Management and Research

29 March 2016

Number of times this article has been viewed

\author{
Alicja Krejner' \\ Malgorzata Litwiniuk ${ }^{1-3}$ \\ Tomasz Grzela' \\ 'Laboratory of Cell Molecular \\ Biology, Department of Histology and \\ Embryology, Biostructure Research \\ Center, Medical University of Warsaw, \\ Warsaw, Poland; ${ }^{2}$ Postgraduate School \\ of Molecular Medicine, Medical \\ University of Warsaw, Warsaw, Poland; \\ ${ }^{3}$ Department of Otolaryngology, \\ Medical University of Warsaw, \\ Warsaw, Poland
}

\begin{abstract}
Matrix metalloproteinases (MMPs) are key effector molecules responsible for extracellular matrix (ECM) turnover. They are involved in tissue remodeling and regeneration. Although the main targets for MMPs are ECM components, they are also able to digest a variety of non-ECM molecules including cytokines, their receptors, or carriers. Therefore, the activity of the MMPs remains under tight control. However, when controlling mechanisms are ineffective, MMPs may become highly dangerous molecules, which have a strong destructive effect on affected tissues. Apart from cancer metastasis, aneurysm formation, or airway remodeling in asthma, MMPs have also been identified as main detrimental factors in delayed healing of chronic wounds. In this short review, we describe main representatives of MMPs family, their role in pathophysiology of chronic wounds, as well as current and possible therapeutic strategies for modulation of MMPs' activity, which may be useful in management of chronic wounds.
\end{abstract}

Keywords: chronic wound, MMPs, MMP inhibitors, wound treatment

\section{Introduction}

Matrix metalloproteinases (MMPs) belong to the family of zinc-dependent endoproteases. MMPs play an important role in physiological turnover of extracellular matrix (ECM). They may digest various components of ECM, including high-molecularweight protein fibers of collagens and elastin, small ECM molecules like fibronectin and aggrecan, and also several non-ECM molecules. MMPs are able to release hidden fragments and neoepitopes from both ECM and non-ECM macromolecules, which may then reveal various bioactivities, even different from those of the source molecules. Thus, members of MMPs family may participate in activation of transforming growth factor (TGF)- $\beta$, Fas ligand, and pro-tumor necrosis factor (TNF), pro-interleukin (IL)-1 $\beta$, pro-IL-8, etc. ${ }^{1}$ Also, MMPs may liberate some cytokines and growth factors, including TGF- $\beta$ and vascular endothelial growth factor, which are entrapped in the ECM net and may require proteolytic discharge from binding proteins.

Furthermore, MMPs may modify cell adhesion to the ECM by processing of various adhesion molecules, dystroglycan, syndecans, etc. ${ }^{2-4}$ The aforementioned properties of MMPs make them the main factors involved in various physiological processes such as tissue remodeling and growth, cell proliferation and migration, angiogenesis, and wound healing..$^{5-7}$ On the other hand, MMPs are also involved in numerous pathological processes. They can contribute to cancer metastasis, aneurysm and varicose vein formation, and airway remodeling in asthma. ${ }^{8-12}$ Moreover, the excessive production and hyperactivity of MMPs is observed in patients with nonhealing chronic wounds. ${ }^{13,14}$
Correspondence: Tomasz Grzela Laboratory of Cell Molecular Biology, Department of Histology and Embryology, Medical University of Warsaw, Chalubinskiego 5, 02-004 Warsaw, Poland Email tomekgrzela@gmail.com (c) (1) (5) $2016 \mathrm{krejner}$ et al. This work is published and licensed by Dove Medical Press Limited. The full terms of this license are available at https://www.dovepress.com/terms. cC. you hereby accept the Terms. Non-commercial uses of the work are permitted without any further permission from Dove Medical Press Limited, provided the work is properly attributed. For permission for commercial use of this work, please see paragraphs 4.2 and 5 of our Terms (https://www.dovepress.com/terms.php). 


\section{MMP structure}

So far, at least 25 members of the MMP family have been described. Traditionally, MMPs are assigned to six groups collagenases, stromelysins, matrilysins, gellatinases, membrane-type MMPs, and others. Recently, new data concerning their molecular structure, mechanism of activation, and substrate specificity have resulted in MMPs being classified differently. According to this new system, MMPs are classified into four groups: gelatinases, matrilysins, archetypal MMPs, and furin-activated MMPs (Table 1).,15

Despite some differences between MMP family members, the general protein structure is similar for all representatives. In general, the $\mathrm{N}$-terminal end of the protein contains a signal peptide. This short leader peptide directs the molecule to the secretory pathway; but after insertion of the maturating molecule into the cistern of the endoplasmic reticulum, the signal sequence is removed. The next part of MMP molecule is the propeptide domain with approximately 80 amino acids. It contains a conserved motif (PRCGXPD), known as "cysteine-switch". The role of this characteristic motif is to block a catalytic site and retain the latent form of MMPs. The next part of the MMP molecule consists of sphere-like domain composed of approximately 160-170 amino acids, containing an exceptional sequence (HEXXHXXGXXH). This catalytic domain contains a large, shallow cleft with two zinc ions inside, which represents an active site of the enzyme. In most MMPs (except for MMP-7, -23, or -26), a short hinge region formed by approximately 10-30 amino acids connects the catalytic domain with a C-terminal fragment, called the hemopexin-like domain. This last domain has

Table I Schematic representation of MMPs family with representatives and their main substrates

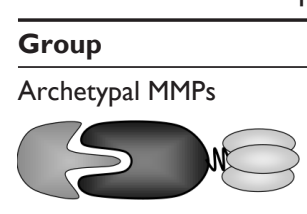

Stromelysins: MMP-3, - 10

Others: MMP-12, - 19, -20, -27

Matrilysins

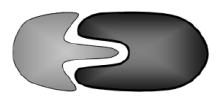

Gelatinases

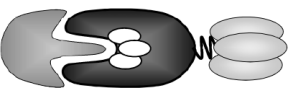

Furin-activated MMPs
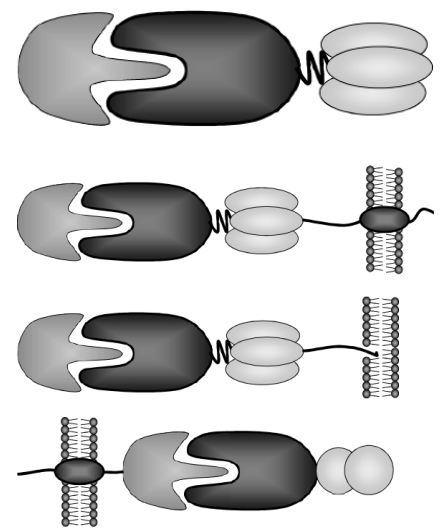

MMP-7, -26

MMP-2, -9

Secreted: MMP-II, -2I, -28

Type I transmembrane: MMP-I4, - I5, - 16, -24

GPI-anchored: MMP-I7, -25

Type II transmembrane:

MMP-23A, -23B
Main substrates

ECM: collagens, gelatin, fibronectin,

aggrecan, etc

Non-ECM: pro-IL-I $\beta$, pro-IL-8, pro-TNF, other MMPs, PAI, IGFBP

ECM: collagens, gelatin, elastin, fibronectin, laminin, aggrecan

Non-ECM: pro-IL-I $\beta$, other MMPs, MMPI

TIMP complex, fibrinogen, plasminogen,

antithrombin III, IGFBP

ECM: collagen IV, gelatin, elastin, fibronectin, laminin

Non-ECM: fibrin, plasminogen, myelin basic protein

ECM: collagen IV, gelatin, elastin, fibronectin, laminin, integrins, etc

Non-ECM: other MMPs, MMP/TIMP complex, fibrinogen, plasminogen

ECM: collagens, gelatin, elastin, fibronectin, etc Non-ECM: pro-IL-I $\beta$, plasminogen, other MMPs

ECM: collagen IV, gelatin, laminin, fibronectin Non-ECM: casein, IGFBP

ECM: collagens, gelatin, elastin, laminin, vitronectin

Non-ECM: other MMPs

UNK

UNK

Abbreviations: ECM, extracellular matrix; GPI, glycosylphosphatidylinositol; IGFBP, insulin-like growth factor-binding protein; IL, interleukin; MMPs, matrix metalloproteinases; non-ECM, other substrates; PAI, plasminogen activator inhibitor; TIMP, tissue inhibitors of metalloproteinase; TNF, tumor necrosis factor; UNK, unknown. 
a length of approximately 200 amino acids and is considered as a docking place for tissue inhibitors of metalloproteinases (TIMPs). ${ }^{16}$ Besides that, the representatives of membrane type (MT) subgroup of MMPs contain either a cellmembrane-anchoring glycosylphosphatidylinositol (GPI) moiety (MMP-17 and -25, known as MT4- and MT6-MMP) or a type I transmembrane segment with a short intracellular tail (MMP-14, -15, -16, and -24, also known as MT-1, -2, -3, and -5-MMP, respectively) (Table 1).

Apart from the aforementioned common components, several MMPs contain some other unique elements. An example may be the fibronectin II-like inserts, attached to the catalytic domain, which are found in MMP-2 and -9 exclusively. Next, the hinge region of MMP-9 is composed of 64 amino acids, which are strongly O-glycosylated. Moreover, in the MMP-23 molecule, the signal peptide from the $\mathrm{N}$-terminus has been replaced by a type II transmembrane domain, whereas the hemopexin-like domain was substituted by a cysteine-rich segment, which forms an immunoglobulinlike domain. Eventually, all the membrane-anchored MMPs and three of the secreted MMPs (MMP-11, -21, and -28) have a specific $\mathrm{R}(\mathrm{X} / \mathrm{R}) \mathrm{KR}$ motif between their prodomain and the catalytic domain. This sequence is recognized and digested by furin, the intracellular serine proteinase, which removes the prodomain from the MMP molecule and leads to its intracellular activation. ${ }^{15}$

\section{MMPs expression and activation}

The critical role of MMPs in physiological reactions and some pathological conditions helps understand the precise control of their expression and activity. Interestingly, among all metalloproteinases, only gelatinases (MMP-2 and -9) are expressed constitutively. In contrast, production of other MMPs is induced, eg, in response to a tissue damage or inflammatory response. The expression of MMP genes is controlled by proinflammatory cytokines (eg, TNF, IL-1 $\beta$, IL-6, etc) and growth factors, including epidermal growth factor, platelet-derived growth factor, TGF- $\beta$, etc. ${ }^{15,17}$

The link between the aforementioned mediators and expression of MMPs is due to the presence of genes in the promoter region encoding MMP sequences recognized by two main transcription factors, nuclear factor $\kappa \mathrm{B}(\mathrm{NF}-\kappa \mathrm{B})$ and activator protein 1 (AP-1). Both transcription factors bind to promoters of the majority of inducible genes; therefore, they interconnect several growth factor- and cytokine-mediated intracellular signaling pathways, resulting in the expression of many molecules, including MMPs, engaged in inflammatory response. ${ }^{12}$
The expression of MMPs is also controlled by another group of transcription factors - Ets family members. In the MMP promoters, they recognize the conserved binding site for polyomavirus enhancer activator protein 3 (PEA-3). Since this target sequence is located close to at least one binding element for AP-1, the presumable interaction between the aforementioned transcription factors may modulate response of the promoter to various stimuli. ${ }^{18}$

Recently, apart from the previously discussed mechanisms, an additional mechanism of MMP expression control has been suggested. The proposed mechanism is based on epigenetic modification of chromatin conformation through its acetylation-deacetylation. Interestingly, it has been found that stimulation with IL-1 $\beta$ or TNF, together with inhibition of histone deacetylase, resulted in increased expression of MMP-3 but reduced the production of MMP-1 and MMP-9. ${ }^{19,20}$

Another issue regarding the mechanisms of MMP expression control is the involvement of mechanotransduction and the role of putative mechanoreceptors or mechanoresponsive elements. ${ }^{21}$ This mechanism may be crucial especially in organs and tissues that are subjected to permanent exposure to dynamic stress, eg, joint cartilage or blood vessels. ${ }^{22}$

Moreover, it is noteworthy that expression of MMPs may also be controlled at the posttranscriptional level by regulation of stability or degradation of mRNA. ${ }^{23}$ Both, at the posttranscriptional and translational level, the expression of MMPs is thought to be negatively regulated by the short molecules of noncoding RNA, called microRNAs (miRs). It has been found that miR-9, miR-133a, and miR-24 bind to the 3'-UTR of MMP-14 (MT1-MMP) mRNA and directly block its translation. ${ }^{24-26}$ On the other hand, downregulation of miR-199a-5p in a murine wound-healing model promoted angiogenesis in acute wounds via Ets-1 derepression and MMP-1 induction, both in vitro and in vivo. ${ }^{27}$

As already mentioned, all members of the MMP family are released as an inactive form - proenzyme. This condition is due to the specific interaction of the cysteine thiol group in the prodomain with the zinc cations from the active site of the catalytic domain, known as the "cysteine switch". The cessation of prodomain influence on the catalytic domain is crucial for proenzyme activation and may take place in two alternative ways (Figure 1).

Thus, the activation of MMPs may result from direct digestion of prodomain by another endoproteinase. This proteolytic activation may be carried by various extracellular proteolytic enzymes, including cysteine, serine, and aspartate proteases or other MMPs. In addition, this pathway involves the intracellular processing and activation of several MMPs 


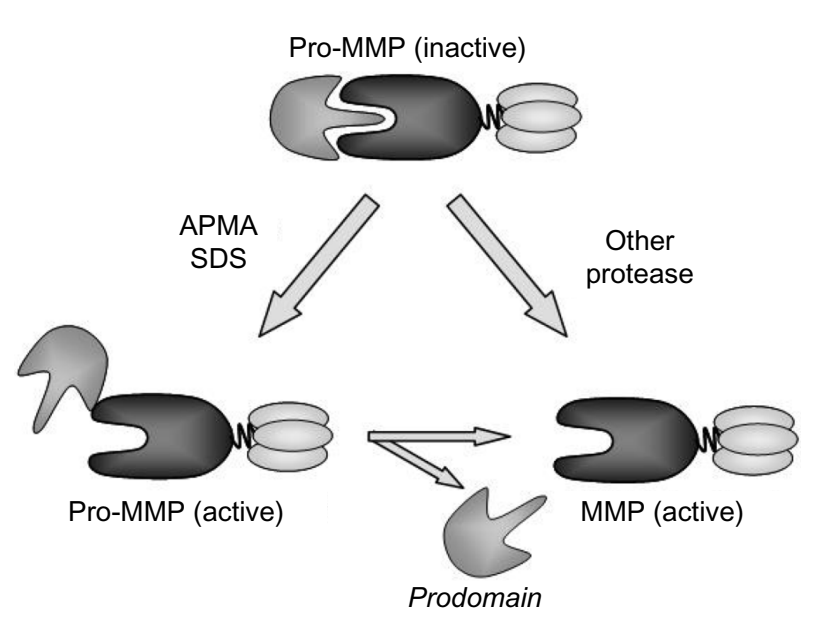

Figure I Two pathways of MMPs activation.

Abbreviations: APMA, aminophenylmercuric acetate; SDS, sodium dodecyl sulfate; MMPs, matrix metalloproteinases.

by furin, the subtilisin-like serine proteinase, in the endoplasmic reticulum and trans-Golgi network. ${ }^{28-30}$

The second pathway is based on modification of the cysteine thiol groups from the fuse-like prodomain by various compounds. Besides free radical and disulfides, some detergents, including sodium dodecyl sulfate (SDS), alkylating agents, heavy metal ions, and organomercurials with 4-aminophenylmercuric acetate, may induce allosteric alteration in MMP structure. This alteration leads to an exposure of the active site of the catalytic domain. Since the prodomain may still stay attached to the entire molecule despite the activation, its molecular weight will remain unchanged. However, usually the prodomain is further removed by autocleavage, and this event results in decrease of MMP molecular size. ${ }^{5,31}$ Very often, both the aforementioned active forms are well visible in substrate-specific zymography with SDS-polyacrylamide gel electrophoresis.

\section{MMPs in wound healing}

The production and activation of MMPs are essential for tissue remodeling and wound healing. Because of their ability to digest ECM and hemidesmosomes, these endoproteinases allow keratinocyte migration to cover the exposed connective tissue. Although various MMPs are involved in the healing process, the order of their expression and activation, called metalloproteinase activation cascade, seems to be strictly controlled at each stage of the wound repair. ${ }^{32}$

The native collagens show characteristic conformation of triple helix, which is highly resistant to digestion by many proteases, with the exception of collagenases. Therefore, collagenases are necessary for initiation of native collagen processing. After initial digestion, the collagen fibers denature to gelatin and become vulnerable to further degradation by other proteinases. This specific proteolysis is necessary for keratinocyte migration and, finally, reepithelialization. ${ }^{33}$

\section{Collagenases (MMP-I, MMP-8, and MMP-I3)}

The main common feature of enzymes from this group is their ability to digest native fibrillar collagens (types I, II, III, $\mathrm{V}$, and XI) into characteristic $\mathrm{N}$-terminal $3 / 4$ and $\mathrm{C}$-terminal $1 / 4$ fragments. ${ }^{15}$ Besides the native collagen fibers, other targets for collagenases include various ECM components and non-ECM molecules - pro-TNF, pro-IL-8, proteaseactivated receptor-1, insulin-like growth factor-binding proteins, etc. ${ }^{1,34,35}$

MMP-1 (collagenase-1) contributes to the migration of skin fibroblasts and basal keratinocytes and thereby promotes the wound-healing process. ${ }^{36}$ The expression of MMP-1 is rapidly induced by the contact of the cells with type I collagen, whereas laminin-1 seems to inhibit MMP-1 production. ${ }^{33,37}$

The activation of MMP-1 requires cooperation with an active MMP-3 or plasminogen activator/plasmin system. ${ }^{38}$ After injury, the highest expression of MMP-1 is observed in basal keratinocytes of the wound edge at day 1 and decreases gradually until the phase of reepithelialization. ${ }^{37}$ However, in patients with nonhealing wounds, the MMP-1 level remains stably high and may contribute to excessive ECM turnover. ${ }^{39}$

MMP-8 (collagenase-2) is another collagenase essential for tissue repair. It is expressed by neutrophils, macrophages, and fibroblasts during wound healing..$^{40}$ On the other hand, abnormally elevated amount of mRNA for MMP-8 in diabetic fibroblasts or increased levels of MMP-8 in wound tissues seem to impair the healing of chronic leg ulcers and diabetic foot ulcers. ${ }^{41-44}$

MMP-13 (collagenase-3) is supposed to be responsible for the regulation of granular tissue growth. ${ }^{45}$ MMP-13 knockout mice have significantly reduced amount of granular tissue with delayed myofibroblasts organization, especially in the later phase of granulation..$^{46}$ Although expression of MMP-13 is very low in acute and normally healing wounds significant amounts of this collagenase may be easily found in chronic venous ulcers.

\section{Gelatinases (MMP-2 and MMP-9)}

MMP-2 (gelatinase A) and MMP-9 (gelatinase B) are mainly responsible for cleavage of denatured collagen and gelatin. ${ }^{47}$ They may also digest various ECM molecules, including several collagen types (I, IV, V, VII, IX, and X), elastin, laminin, aggrecan, fibronectin, vitronectin, and several non-ECM molecules, including pro-TNF, TGF- $\beta$, pro-IL-1 $\beta$, 
and pro-IL-8. ${ }^{12,15}$ Also, they are engaged in processing of various pro- and antiangiogenic factors during wound healing, especially during early stages of this process. ${ }^{3,48}$

Both gelatinases are constitutively synthesized by many cells, including fibroblasts, keratinocytes, endothelial cells, polymorphonuclear leukocytes, and monocytes. The increased expression of MMP-2 can be detected in the connective tissue, fibroblasts, and endothelium at the edge of acute wounds during all stages of the healing process. ${ }^{48}$ It is hypothesized that MMP-2 induces epithelial cell migration by specific cleavage of laminin-5, a component of the epithelial basement membrane. ${ }^{49}$ The MMP-2 activity remains fairly stable until the phase of reepithelialization..$^{50,51}$

MMP-9 contributes to wound healing by initiation of keratinocytes migration and mobilization of endothelial progenitor cells from the bone marrow. In murine model of wound healing, mice lacking MMP-9 showed reduced endothelial progenitor cell mobilization and vasculogenesis in damaged tissue..$^{52}$ The maximal level of MMP-9 is observed at the edges of the wound at 24 hours after an injury and decreases significantly by 48 hours. ${ }^{53}$ Although gelatinases are essential for proper wound healing, the increased levels of both MMP-2 and -9 in wound fluid correlate with severity of chronic ulcers. ${ }^{14}$ Excessive activity of these MMPs in the wound microenvironment is supposed to impair tissue turnover and results in delayed wound closure. ${ }^{13,54,55}$

\section{MMP-I 4 (MTI-MMP)}

MMP-14 is the main representative of type I transmembrane MMPs. It digests native type I collagen into three-quarter and one-quarter excerpts, in a collagenase-specific manner. Also, MMP-14 is able to process the main components of ECM collagens (type II and III), gelatin, fibronectin, and also several non-ECM molecules, including $\alpha_{2}$-macroglobulin, hyaluronan receptor (CD44), and myelin-inhibitory protein. ${ }^{15}$ Furthermore, MMP-14 plays an important role in the proteolytic activation of pro-MMP-2. ${ }^{56} \mathrm{MMP}-14$ may be present on the surface of vascular smooth muscle cells and activated macrophages. However, in later phases of wound repair, the keratinocytes in the migrating front of the regenerating epithelium are considered as the most important producers of MMP-14. ${ }^{57-59}$ The lack of MMP-14 not only leads to defective turnover of type I collagen, but also decreased level of active MMP-2, which may finally impair wound healing. ${ }^{60}$

\section{Stromelysins (MMP-3 and MMP-10)}

Stromelysins have molecular structure analogous to that of collagenases, but in contrast to them, stromelysins cannot digest native collagens. Their main substrates are processed collagens (III, IV, V, IX, and X), gelatin, laminin, fibronectin, proteoglycans, and many other non-ECM molecules, including plasminogen, fibrinogen, IL-1 $\beta$, etc. ${ }^{1}$ Despite similar substrate specificity, both stromelysins differ in their efficacy.

MMP-3 (stromelysin-1) has higher proteolytic activity than MMP-10. In addition, MMP-3 may activate other proMMPs (collagenases or gelatinases) by deletion of their prodomain. Therefore, MMP-3 is recognized as a key factor in activation of these MMPs. ${ }^{47,61}$ The expression of MMP-3 is detected in dermal fibroblasts and basal keratinocytes at the sites of epidermis proliferation, but not at the migrating front. ${ }^{62}$ This stromelysin is supposed to initiate contraction of the dermis by fibroblasts. ${ }^{63}$ Interestingly, in MMP-3 knockout mice, despite improper arrangement of actin-rich stromal fibroblasts, cell migration and wound reepithelialization remain unaffected. ${ }^{64}$ Nevertheless, in the course of an inflammatory reaction, the expression of MMP-3 may be further enhanced by some cytokines, eg, interferon (IFN)- $\gamma$, thus resulting in imbalance between this protease and its inhibitors and, consequently, an impairment of the wound healing. ${ }^{65}$

MMP-10 (stromelysin-2), in contrast to MMP-3, is detected only in basal keratinocytes at the wound edge. ${ }^{62}$ Although a constant release of active MMP-10 in transgenic mice does not alter skin architecture or prolong the healing time, it leads to abnormal organization of the wound epithelium and reduced deposition of new ECM. ${ }^{66}$ MMP-10 expression is associated with proline-rich protein tyrosine kinase 2 (Pyk2)-dependent pathway. In murine model, a Pyk2 overexpression correlated with an increase in MMP-10 level and faster healing of experimental wounds. ${ }^{67}$

The few aforementioned examples of MMPs concerned only the most extensively studied representatives involved in chronic wound biology. Noteworthy further studies exploiting knockout animal models still provide new data expanding our knowledge regarding highly complex MMPs system and its involvement in physiology and pathology. ${ }^{15}$ However, their detailed description is out of scope of this concise review.

\section{MMPs inhibition - therapeutic perspectives}

As mentioned previously, in physiological conditions, MMPs remain under very precise control. Nevertheless, if this control appears insufficient, MMPs may become very dangerous effector molecules, involved in several pathologies, including metastatic cancer, vascular disorders, or chronic wounds. Therefore, it is obvious that mechanisms engaged in this regulation may be potential targets for novel therapeutic approach (Figure 2). 


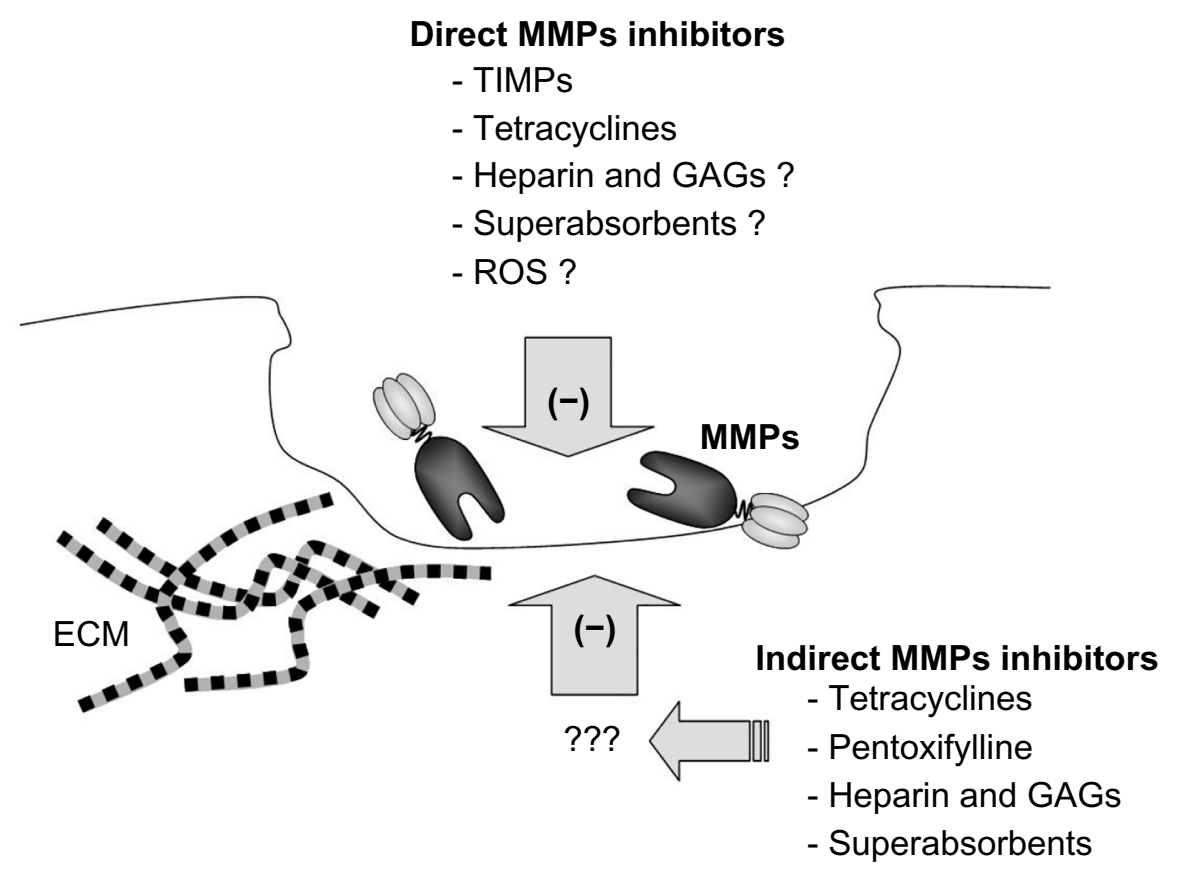

Figure 2 The main groups of MMPs inhibitors.

Abbreviations: ECM, extracellular matrix; GAGs, glycosaminoglycans; MMPs, matrix metalloproteinases; ROS, reactive oxygen species; TIMPs, tissue inhibitors of metalloproteinases; ???, unknown mechanisms involved; ?, exact mechanism unclear; (-), inhibition.

Physiological mechanisms of MMPs inhibition involve their interaction with the previously mentioned specific inhibitors called TIMPs, or several other endogenous inhibitors. The last group includes $\alpha 2$-macroglobulin, serine proteinase inhibitors (serpins), tissue factor-pathway inhibitor 2, reversion-inducing cysteine-rich protein with Kazal motifs (RECK), and others. ${ }^{68}$

\section{TIMPs}

TIMPs (TIMP-1, -2, -3, and -4) are considered as "classical" endogenous inhibitors of MMPs $\left(K_{\mathrm{i}}\right.$ at the level of $10^{-11} \mathrm{M}$ for interaction between TIMP-1/MMP-1). The mechanism of their action is based on chelating of zinc ions from the catalytic domain of MMP. ${ }^{69}$ At first, TIMPs dock to the hemopexin domain of MMPs. Next, they bind to the catalytic domain and, finally, remove zinc cations from the active site, thus disrupting its enzymatic activity.

In general, various TIMPs differ in their affinity to specific MMPs, eg, TIMP-1 mainly binds to MT-MMPs, whereas other members of TIMPs family are less selective. It is noteworthy that an interaction between TIMP molecules and active MMPs in vivo is difficult to analyze due to the presence of $\alpha 2$-macroglobulin, a powerful MMP-neutralizing protein. . $^{29,31}$

As mentioned previously, the main role of TIMPs is the inhibition of MMPs activity. However, as reported for TIMP-2 and for other representatives of this family, the TIMP- mediated bridging between MT1-MMP and hemopexin domain of pro-MMP-2 is essential for the activation of this gelatinase. $^{5}$

TIMPs are expressed and released by various cell populations, including macrophages, platelets, or vascular smooth muscle cells. In normally healing wounds, the expression of TIMP-1 and -3 mRNAs was detected in proliferating keratinocytes between the third and fifth day after injury. ${ }^{70}$ In case of chronic wounds, the expression pattern of TIMPs is altered. The lack of TIMP-2 in the zone with migrating keratinocytes of the wound edges may lead to uncontrolled activation of MMP-2 in chronic ulcers. ${ }^{70}$ Furthermore, in the chronic wound fluid, the level of TIMP-2 is significantly lower in comparison to the healing group. ${ }^{71}$ However, instead of absolute amounts of MMPs or TIMPs, the MMP/TIMP ratio seems to be a better predicting factor for the wound healing; for example, the initial MMP-9/TIMP-1 ratio revealed inverse correlation with healing of pressure ulcers in a 36-week-long observation. $^{72}$

Since TIMPs promote the migration of human keratinocytes in vitro, their in vivo effectiveness after topical application was verified in murine wound model. Indeed, recombinant human TIMP-2 (rh-TIMP-2) accelerated the wound closure in diabetic mice, whereas a GPI-anchored modification of TIMP-1 (TIMP-1-GPI) increased the rate of healing in an excisional wound model in humans. ${ }^{73,74}$ 
Recently, in addition to TIMPs, several other MMP modulators, including both natural and synthetic agents, have been widely investigated. These studies concerned MMP-inhibitory properties of various natural compounds, eg, some antibiotics, curcumin, green tea polyphenols, or resveratrol, as well as many synthetic inhibitors, including phenantroline, hydroxamic acid, carboxylic acid, ethylenediaminetetraacetic acid, and thiazoles. ${ }^{75,76}$ Although some of these exogenous inhibitors are widely used in current clinical practice, it is noteworthy that their original applications did not concern modulation of MMPs activity.

The first group of drugs, consciously developed as broadspectrum MMP inhibitors, comprised zinc ion-chelating hydroxamate derivatives, including batimastat, marimastat, and ilomastat. They were designed as antimetastatic, anticancer drugs. However, regardless of very promising results of preclinical studies, owing to relatively low therapeutic effectiveness accompanied by various adverse reactions, their routine clinical use was discontinued. ${ }^{12,77}$

\section{Tetracyclines}

Tetracyclines, the group of natural antibiotics isolated from Streptomyces, are known for their various nonantimicrobial properties, including anti-inflammatory and immunomodulatory actions, as well as inhibition of proteolysis. The main representative tetracycline is doxycycline, which has been shown to stabilize ECM turnover and support chronic wound healing. According to Serra et $\mathrm{a}^{17}$, oral doxycycline administration in a subantimicrobial daily dose (40 $\mathrm{mg}$ for 3 months) accelerated the healing of chronic venous leg ulcers, presumably through the inhibition of MMP-9. Similar effects have been observed after 3-month treatment with minocycline, another tetracycline family representative, at an oral daily dose of $100 \mathrm{mg} .{ }^{79}$ It was suggested that doxycycline and minocycline inhibit MMPs directly by blockage of their catalytic site. In addition, tetracyclines are supposed to reduce the expression of MMPs indirectly by attenuating the inflammatory cascade. ${ }^{80,81}$

\section{Heparin and glycosaminoglycans}

The inhibitory influence on MMP activity, especially MMP9, was also demonstrated both in vitro and in vivo in case of heparin and glycosaminoglycan (GAG)-sulodexide. , $^{89,82-85}$ Some authors have postulated the complex indirect inhibitory influence of heparin and GAG-sulodexide on MMPs (revealed especially by low-molecular-weight heparin fraction). ${ }^{12,82}$ However, there are also data suggesting direct inhibitory properties of dermatan sulfate fraction in sulo- dexide. ${ }^{7,84}$ Recently, the role of interaction between MMPs and endogenous GAGs was postulated as the important mechanism in the development of vascular pathologies, especially chronic venous disease and venous leg ulcers. . $^{7,84}$ Therefore, the use of heparin and heparin derivatives may offer substantial benefit in therapy and, possibly, prophylaxis of vascular diseases, including chronic wounds. ${ }^{86}$ However, this topic still requires extensive research.

\section{Pentoxifylline}

Pentoxifylline (PTX), a trisubstituted xanthine derivative, may also have some beneficial influence in systemic wound treatment. Because of its dose-related hemorrheologic effects (decreasing blood viscosity and improving erythrocyte flexibility), PTX is mainly used in patients with chronic peripheral arterial disease. ${ }^{87,88}$ However, systemic administration of PTX was also found to accelerate wound healing, presumably because of its anti-inflammatory properties. PTX also has the ability to reduce expressions of MMP-1 and MMP-3, whereas it increases expression of TIMP- $1 .{ }^{89}$

\section{Superabsorbent polymers}

Besides proper systemic therapy, successful wound management requires an effective local treatment. Therefore, in recent years, several technologically advanced products, referred to as composite or hybrid dressings have been developed. Owing to their multilayered structure, they combine properties of different materials. The majority of them consist of gel-forming superabsorbent polymers (sodium polyacrylate or sodium carboxymethylcellulose), which absorb excessive amounts of wound exudate. Thus, in addition to reduced skin maceration, they may decrease the local amount of bacterial proteases and endogenous proteolytic enzymes, including MMPs. This mechanism may better explain the significant clinical effectiveness of these products in vivo. Presumably, the attenuation of proteolytic activity is due to the simple locking of the mentioned proteases in the gel-like structure of the absorbent layer. ${ }^{90-92}$ However, direct inhibition of MMPs by chelating $\mathrm{Zn}^{2+}$ or $\mathrm{Ca}^{2+}$ ions in polyacrylate or carboxymethylcellulose should also be considered.

A very similar mechanism of action was suggested in case of a new class wound care product - an enzyme-alginogel, Flaminal (Flen Pharma, Kontich, Belgium). This novel dressing has a broad spectrum of antimicrobial activity, prevents skin maceration and irritation, and also seems to absorb and neutralize MMPs. ${ }^{93}$ It directly inhibited recombinant human MMP-2 and -9 activity in vitro in a dose-dependent 
manner. Moreover, this mechanism was also confirmed in vivo in venous leg ulcers study. The activity of both MMPs in exudates collected from patients with Flaminal-treated wounds was lower than that from control group..$^{55}$

\section{Amniotic membrane}

Another interesting solution to chronic wound therapy may be the use of biological dressings prepared from the fresh or processed amniotic membrane. ${ }^{94,95}$ An application of the amnion in vivo results in stimulation of granular tissue formation and faster reepithelialization, but also less-pronounced irritation of the periwound skin. ${ }^{96}$ Apart from keratinocyte stimulation, the multidirectional beneficial impact of the amnion dressing on the wounds includes also the inhibition of excessive MMPs activity. ${ }^{97}$ As shown in experimental in vitro conditions, the amniotic membrane extracts revealed a strong protease modulatory potential, possibly due to the presence of several potent natural MMP inhibitors including TIMP-1, type-1 plasminogen activator inhibitor (PAI-1), or thrombospondin-1 (TSP-1). ${ }^{96}$

\section{Hypoxia and oxygen}

In chronic wounds, an imbalance between MMPs and their inhibitors may also result from ischemia-reperfusion injury and hypoxia. ${ }^{98}$ However, the response to decreased oxygen level may vary among different cell types, especially keratinocytes, monocytes, and fibroblasts. In human keratinocytes exposed to hypoxia, the secretion of MMP-2, MMP-9, and TIMP-2 was reduced, whereas in human monocytes, decrease of MMP-9 and increase of TIMP-1 were observed. ${ }^{99,100}$

On the other hand, studies on the role of hypoxic microenvironment in chronic inflammation provided some evidence that the topical administration of exogenous oxygen might be a novel option for wound treatment. New carriers of oxygen, known as oxygen-loaded nanodroplets (OLNs), are considered as an effective way for MMP/TIMP ratio normalization. Indeed, chitosan- and dextran-shelled OLNs prevented detrimental effects of hypoxia on MMPs and TIMPs secretion and restored their balance in human keratinocytes and monocytes. ${ }^{99,100}$ Furthermore, OLNs promoted proangiogenic phenotype in hypoxic human dermal endothelium, which can also result from restoration of appropriate MMP/ TIMP balance. ${ }^{101}$

On the other hand, reactive oxygen species, which are well known as endogenous triggers of autolytic activation of MMPs, may also inhibit metalloproteinases by alteration of amino acids at their active site. ${ }^{29,31}$ However, the better identification of the exact role of oxygen and reactive oxygen species in the pathophysiology of chronic wounds still requires further studies.

\section{Conclusion}

MMPs are key molecules in tissue remodeling and regeneration. Although they are necessary for proper wound healing, an excessive amount of MMPs or an imbalance between MMPs and their natural inhibitors can impair the healing process. Therefore, better regulation of MMPs activity may offer an attractive therapeutic perspective in chronic wound management. Indeed, recently, several novel therapeutic strategies with use of MMP modulators were developed. However, these concepts still require further extensive studies.

\section{Disclosure}

The authors report no conflicts of interest in this work.

\section{References}

1. Amălinei C, Căruntu ID, Bălan RA. Biology of metalloproteinases. Rom J Morphol Embryol. 2007;48(4):323-334.

2. Endo K, Takino T, Miyamori H, et al. Cleavage of syndecan-1 by membrane type matrix metalloproteinase-1 stimulates cell migration. J Biol Chem. 2003;278(42):40764-40770.

3. Mott JD, Werb Z. Regulation of matrix biology by matrix metalloproteinases. Curr Opin Cell Biol. 2004;16(5):558-564.

4. Yamada H, Saito F, Fukuta-Ohi H, et al. Processing of beta-dystroglycan by matrix metalloproteinase disrupts the link between the extracellular matrix and cell membrane via the dystroglycan complex. Hum Mol Genet. 2001;10(15):1563-1569.

5. Hadler-Olsen E, Fadnes B, Sylte I, Uhlin-Hansen L, Winberg JO. Regulation of matrix metalloproteinase activity in health and disease. FEBS J. 2011;278(1):28-45.

6. Ravanti L, Kahari VM. Matrix metalloproteinases in wound repair (review). Int J Mol Med. 2000;6(4):391-407.

7. Mannello F, Raffetto JD. Matrix metalloproteinase activity and glycosaminoglycans in chronic venous disease: the linkage among cell biology, pathology and translational research. Am J Transl Res. 2011;3(2):149-158.

8. Kucukguven A, Khalil RA. Matrix metalloproteinases as potential targets in the venous dilation associated with varicose veins. Curr Drug Targets. 2013;14(3):287-324.

9. Raffetto JD, Mannello F. Pathophysiology of chronic venous disease. Int Angiol. 2014;33(3):212-221.

10. Grzela K, Litwiniuk M, Zagorska W, Grzela T. Airway remodeling in chronic obstructive pulmonary disease and asthma: the role of matrix metalloproteinase-9. Arch Immunol Ther Exp (Warsz). 2016;64(1):47-55.

11. Shiomi T, Okada Y. MT1-MMP and MMP-7 in invasion and metastasis of human cancers. Cancer Metastasis Rev. 2003;22(2-3):145-152.

12. Grzela T, Bikowska B, Litwiniuk M. Matrix metalloproteinases in aortic aneurysm - executors or executioners? In: Grundmann RT, editor. Etiology, Pathogenesis and Pathophysiology of Aortic Aneurysms and Aneurysm Rupture. Rijeka, Croatia: Intech Publ; 2011:25-54.

13. Wysocki AB, Staiano-Coico L, Grinnell F. Wound fluid from chronic leg ulcers contains elevated levels of metalloproteinases MMP-2 and MMP-9. J Invest Dermatol. 1993;101(1):64-68.

14. Rayment EA, Upton Z, Shooter GK. Increased matrix metalloproteinase-9 (MMP-9) activity observed in chronic wound fluid is related to the clinical severity of the ulcer. Br J Dermatol. 2008;158(5): 951-961. 
15. Fanjul-Fernández M, Folgueras AR, Cabrera S, López-Otín C. Matrix metalloproteinases: evolution, gene regulation and functional analysis in mouse model. Biochim Biophys Acta. 2010;1803(1):3-19.

16. Nagase H, Visse R, Murphy G. Structure and function of matrix metalloproteinases and TIMPs. Cardiovasc Res. 2006;69(3):562-573.

17. Yan C, Boyd DD. Regulation of matrix metalloproteinase gene expression. J Cell Physiol. 2007;211(1):19-26.

18. Kapila S, Xie Y, Wang W. Induction of MMP-1 (collagenase-1) by relaxin in fibrocartilaginous cells requires both the AP-1 and PEA-3 promoter sites. Orthod Craniofac Res. 2009;12(3):178-186.

19. Clark IM, Swingler TE, Sampieri CL, Edwards DR. The regulation of matrix metalloproteinases and their inhibitors. Int J Biochem Cell Biol. 2008;40(6-7):1362-1378.

20. Clark IM, Swingler TE, Young DA. Acetylation in the regulation of metalloproteinase and tissue inhibitor of metalloproteinases gene expression. Front Biosci. 2007;12:528-535.

21. Wiegand C, White R. Microdeformation in wound healing. Wound Repair Regen. 2013;21(6):793-799.

22. Blain EJ. Mechanical regulation of matrix metalloproteinases. Front Biosci. 2007;12:507-527.

23. Chakraborti S, Mandal M, Das S, Mandal A, Chakraborti T. Regulation of matrix metalloproteinases: an overview. Mol Cell Biochem. 2003;253(1-2):269-285.

24. Di Gregoli K, Jenkins N, Salter R, White S, Newby AC, Johnson JL. MicroRNA-24 regulates macrophage behavior and retards atherosclerosis. Arterioscler Thromb Vasc Biol. 2014;34(9):1990-2000.

25. Zhang H, Qi M, Li S, et al. microRNA-9 targets matrix metalloproteinase 14 to inhibit invasion, metastasis, and angiogenesis of neuroblastoma cells. Mol Cancer Ther. 2012;11(7):1454-1466.

26. Xu M, Wang YZ. miR-133a suppresses cell proliferation, migration and invasion in human lung cancer by targeting MMP-14. Oncol Rep. 2013;30(3):1398-1404.

27. Chan YC, Roy S, Huang Y, Khanna S, Sen CK. The microRNA miR199a-5p down-regulation switches on wound angiogenesis by derepressing the v-ets erythroblastosis virus E26 oncogene homolog 1-matrix metalloproteinase-1 pathway. J Biol Chem. 2012;287(49):41032-41043.

28. Klein T, Bischoff R. Physiology and pathophysiology of matrix metalloproteases. Amino Acids. 2011;41(2):271-290.

29. Ra HJ, Parks WC. Control of matrix metalloproteinase catalytic activity. Matrix Biol. 2007;26(8):587-596.

30. Pei D, Weiss SJ. Furin-dependent intracellular activation of the human stromelysin-3 zymogen. Nature. 1995;375(6528):244-247.

31. Fu X, Parks WC, Heinecke JW. Activation and silencing of matrix metalloproteinases. Semin Cell Dev Biol. 2008;19(1):2-13.

32. Young PK, Grinnell F. Metalloproteinase activation cascade after burn injury: a longitudinal analysis of the human wound environment. J Invest Dermatol. 1994;103(5):660-664.

33. Pilcher BK, Dumin JA, Sudbeck BD, Krane SM, Welgus HG, Parks WC. The activity of collagenase- 1 is required for keratinocyte migration on a type I collagen matrix. J Cell Biol. 1997;137(6):1445-1457.

34. Gearing AJ, Beckett P, Christodoulou M, et al. Processing of tumour necrosis factor-alpha precursor by metalloproteinases. Nature. 1994;370(6490):555-557.

35. Boire A, Covic L, Agarwal A, Jacques S, Sherifi S, Kuliopulos A. PAR1 is a matrix metalloprotease-1 receptor that promotes invasion and tumorigenesis of breast cancer cells. Cell. 2005;120(3): 303-313.

36. Cho JW, Kang MC, Lee KS. TGF- $\beta 1$-treated ADSCs-CM promotes expression of type I collagen and MMP-1, migration of human skin fibroblasts, and wound healing in vitro and in vivo. Int J Mol Med. 2010;26(6): 901-906

37. Sudbeck BD, Pilcher BK, Welgus HG, Parks WC. Induction and repression of collagenase-1 by keratinocytes is controlled by distinct components of different extracellular matrix compartments. J Biol Chem. 1997;272(35):22103-22110.

38. Berman MB. Regulation of corneal fibroblast MMP-1 collagenase secretion by plasmin. Cornea. 1993;12(5):420-432.
39. Muller M, Trocme C, Lardy B, Morel F, Halimi S, Benhamou PY. Matrix metalloproteinases and diabetic foot ulcers: the ratio of MMP-1 to TIMP-1 is a predictor of wound healing. Diabet Med. 2008;25(4):419-426.

40. Gutiérrez-Fernández A, Inada M, Balbín M, et al. Increased inflammation delays wound healing in mice deficient in collagenase-2 (MMP-8). FASEB J. 2007;21(10):2580-2591.

41. Burrow JW, Koch JA, Chuang HH, Zhong W, Dean DD, Sylvia VL. Nitric oxide donors selectively reduce the expression of matrix metalloproteinases- 8 and -9 by human diabetic skin fibroblasts. J Surg Res. 2007;140(1):90-98.

42. Nwomeh BC, Liang HX, Cohen IK, Yager DR. MMP-8 is the predominant collagenase in healing wounds and nonhealing ulcers. J Surg Res. 1999;81(2):189-195.

43. Lobmann R, Ambrosch A, Schultz G, Waldmann K, Schiweck S, Lehnert H. Expression of matrix-metalloproteinases and their inhibitors in the wounds of diabetic and non-diabetic patients. Diabetologia. 2002;45(7):1011-1016.

44. Danielsen PL, Holst AV, Maltesen HR, et al. Matrix metalloproteinase- 8 overexpression prevents proper tissue repair. Surgery. 2011;150(5):897-906.

45. Vaalamo M, Mattila L, Johansson N, et al. Distinct populations of stromal cells express collagenase-3 (MMP-13) and collagenase-1 (MMP-1) in chronic ulcers but not in normally healing wounds. $J$ Invest Dermatol. 1997;109(1):96-101.

46. Toriseva M, Laato M, Carpén O, et al. MMP-13 regulates growth of wound granulation tissue and modulates gene expression signatures involved in inflammation, proteolysis, and cell viability. PLoS One. 2012;7(8):e42596.

47. Visse R, Nagase H. Matrix metalloproteinases and tissue inhibitors of metalloproteinases: structure, function, and biochemistry. Circ Res. 2003;92(8):827-839.

48. Salo T, Mäkelä M, Kylmäniemi M, Autio-Harmainen H, Larjava H. Expression of matrix metalloproteinase-2 and -9 during early human wound healing. Lab Invest. 1994;70(2):176-182.

49. Giannelli G, Falk-Marzillier J, Schiraldi O, Stetler-Stevenson WG, Quaranta V. Induction of cell migration by matrix metalloprotease-2 cleavage of laminin-5. Science. 1997;277(5323):225-228.

50. Agren MS. Gelatinase activity during wound healing. Br J Dermatol. 1994;131(5):634-640

51. Caley MP, Martins VL, O'Toole EA. Metalloproteinases and wound healing. Adv Wound Care. 2015;4(4):225-234.

52. Balaji S, Han N, Moles C, et al. Angiopoietin-1 improves endothelial progenitor cell-dependent neovascularization in diabetic wounds. Surgery. 2015;158(3):846-856.

53. Tarlton JF, Vickery CJ, Leaper DJ, Bailey AJ. Postsurgical wound progression monitored by temporal changes in the expression of matrix metalloproteinase-9. Br J Dermatol. 1997;137(4):506-516.

54. Weckroth M, Vaheri A, Lauharanta J, Sorsa T, Konttinen YT. Matrix metalloproteinases, gelatinase and collagenase, in chronic leg ulcers. J Invest Dermatol. 1996;106(5):1119-1124.

55. Grzela T, Niderla-Bielinska J, Litwiniuk M, White R. The direct inhibition of MMP-2 and MMP-9 by an enzyme alginogel: a possible mechanism of healing support for venous leg ulcers. $J$ Wound Care. 2014;23(5):278-285.

56. Pulyaeva H, Bueno J, Polette M, et al. MT1-MMP correlates with MMP-2 activation potential seen after epithelial to mesenchymal transition in human breast carcinoma cells. Clin Exp Metastasis. 1997;15(2):111-120.

57. Seiki M. The cell surface: the stage for matrix metalloproteinase regulation of migration. Curr Opin Cell Biol. 2002;14(5):624-632.

58. Madlener M, Parks WC, Werner S. Matrix metalloproteinases (MMPs) and their physiological inhibitors (TIMPs) are differentially expressed during excisional skin wound repair. Exp Cell Res. 1998;242(1):201-210.

59. Soo C, Shaw WW, Zhang X, Longaker MT, Howard EW, Ting K. Differential expression of matrix metalloproteinases and their tissuederived inhibitors in cutaneous wound repair. Plast Reconstr Surg. 2000;105(2):638-647. 
60. Holmbeck K, Bianco P, Caterina J, et al. MT1-MMP-deficient mice develop dwarfism, osteopenia, arthritis, and connective tissue disease due to inadequate collagen turnover. Cell. 1999;99(1):81-92.

61. Suzuki K, Enghild JJ, Morodomi T, Salvesen G, Nagase H. Mechanisms of activation of tissue procollagenase by matrix metalloproteinase 3 (stromelysin). Biochemistry. 1990;29(44):10261-10270.

62. Saarialho-Kere UK, Pentland AP, Birkedal-Hansen H, Parks WC, Welgus HG. Distinct populations of basal keratinocytes express stromelysin-1 and stromelysin-2 in chronic wounds. J Clin Invest. 1994;94(1):79-88.

63. Bullard KM, Mudgett J, Scheuenstuhl H, Hunt TK, Banda MJ. Stromelysin-1-deficient fibroblasts display impaired contraction in vitro. J Surg Res. 1999;84(1):31-34.

64. Bullard KM, Lund L, Mudgett JS, et al. Impaired wound contraction in stromelysin-1-deficient mice. Ann Surg. 1999;230(2):260-265.

65. Tamai K, Ishikawa H, Mauviel A, Uitto J. Interferon-gamma coordinately upregulates matrix metalloprotease (MMP)-1 and MMP-3, but not tissue inhibitor of metalloproteases (TIMP), expression in cultured keratinocytes. J Invest Dermatol. 1995;104(3):384-390.

66. Krampert M, Bloch W, Sasaki T, et al. Activities of the matrix metalloproteinase stromelysin-2 (MMP-10) in matrix degradation and keratinocytes organization in wounded skin. Mol Biol Cell. 2004;15(12):5242-5254.

67. Koppel AC, Kiss A, Hindes A, et al. Delayed skin wound repair in proline-rich protein tyrosine kinase 2 knockout mice. Am J Physiol Cell Physiol. 2014;306(10):C899-C909.

68. Maskos K, Bode W. Structural basis of matrix metalloproteinases and tissue inhibitors of metalloproteinases. Mol Biotechnol. 2003; 25(3):241-266

69. Bode W, Maskos K. Structural basis of the matrix metalloproteinases and their physiological inhibitors, the tissue inhibitors of metalloproteinases. Biol Chem. 2003;384(6):863-872.

70. Vaalamo M, Leivo T, Saarialho-Kere U. Differential expression of tissue inhibitors of metalloproteinases (TIMP-1, -2, -3, and -4) in normal and aberrant wound healing. Hum Pathol. 1999;30(7):795-802.

71. Mwaura B, Mahendran B, Hynes N, et al. The impact of differential expression of extracellular matrix metalloproteinase inducer, matrix metalloproteinase-2, tissue inhibitor of matrix metalloproteinase-2 and PDGF-AA on the chronicity of venous leg ulcers. Eur J Vasc Endovasc Surg. 2006;31(3):306-310.

72. Ladwig GP, Robson MC, Liu R, Kuhn MA, Muir DF, Schultz GS. Ratios of activated matrix metalloproteinase- 9 to tissue inhibitor of matrix metalloproteinase- 1 in wound fluids are inversely correlated with healing of pressure ulcers. Wound Repair Regen. 2002;10(1):26-37.

73. Terasaki K, Kanzaki T, Aoki T, Iwata K, Saiki I. Effects of recombinant human tissue inhibitor of metalloproteinases-2 (rh-TIMP-2) on migration of epidermal keratinocytes in vitro and wound healing in vivo. J Dermatol. 2003;30(3):165-172.

74. Djafarzadeh R, Conrad C, Notohamiprodjo S, et al. Cell surface engineering using glycosylphosphatidylinositol anchored tissue inhibitor of matrix metalloproteinase-1 stimulates cutaneous wound healing. Wound Repair Regen. 2014;22(1):70-76.

75. Mannello F. Natural bio-drugs as matrix metalloproteinase inhibitors: new perspectives on the horizon? Recent Pat Anticancer Drug Discov. 2006;1(1):91-103.

76. Mannello F, Medda V. Nuclear localization of matrix metalloproteinases. Prog Histochem Cytochem. 2012;47(1):27-58.

77. Baxter BT. Could medical intervention work for aortic aneurysms? Am J Surg. 2004;188(6):628-632.

78. Serra R, Gallelli L, Buffone G, et al. Doxycycline speeds up healing of chronic venous ulcers. Int Wound J. 2015;12(2):179-184.

79. Serra R, Grande R, Buffone G, Gallelli L, De Franciscis S. The effects of minocycline on extracellular matrix in patients with chronic venous leg ulcers. Acta Phlebologica. 2013;14(3):99-107.

80. García RA, Pantazatos DP, Gessner CR, Go KV, Woods VL Jr, Villarreal FJ. Molecular interactions between matrilysin and the matrix metalloproteinase inhibitor doxycycline investigated by deuterium exchange mass spectrometry. Mol Pharmacol. 2005;67(4):1128-1136.
81. Castro MM, Tanus-Santos JE, Gerlach RF. Matrix metalloproteinases: targets for doxycycline to prevent the vascular alterations of hypertension. Pharmacol Res. 2011;64(6):567-572.

82. Grzela T, Brawura-Biskupski-Samaha R, Jelenska MM, Szmidt J. Low molecular weight heparin treatment decreases MMP-9 plasma activity in patients with abdominal aortic aneurysm. Eur J Vasc Endovasc Surg. 2008;35(2):159-161.

83. Mannello F, Jung K, Tonti GA, Canestrari F. Heparin affects matrix metalloproteinases and tissue inhibitors of metalloproteinases circulating in peripheral blood. Clin Biochem. 2008;41(18): 1466-1473.

84. Mannello F, Medda V, Ligi D, Raffetto JD. Glycosaminoglycan sulodexide inhibition of MMP-9 gelatinase secretion and activity: possible pharmacological role against collagen degradation in vascular chronic diseases. Curr Vasc Pharmacol. 2013;11(3):354-365.

85. Mannello F, Ligi D, Canale M, Raffetto JD. Sulodexide down-regulates the release of cytokines, chemokines, and leukocyte colony stimulating factors from human macrophages: role of glycosaminoglycans in inflammatory pathways of chronic venous disease. Curr Vasc Pharmacol. 2014;12(1):173-185.

86. Coccheri S, Mannello F. Development and use of sulodexide in vascular diseases: implications for treatment. Drug Des Devel Ther. 2013;8:49-65.

87. Di Perri T, Carandente O, Vittoria A, Guerrini M, Messa GL. Studies of the clinical pharmacology and therapeutic efficacy of pentoxifylline in peripheral obstructive arterial disease. Angiology. 1984;35(7): 427-435.

88. Słoczyńska K, Kózka M, Pękala E, Marchewka A, Marona H. In vitro effect of pentoxifylline and lisofylline on deformability and aggregation of red blood cells from healthy subjects and patients with chronic venous disease. Acta Biochim Pol. 2013;60(1):129-135.

89. Babaei S, Bayat M. Pentoxifylline accelerates wound healing process by modulating gene expression of MMP-1, MMP-3, and TIMP-1 in normoglycemic rats. J Invest Surg. 2015;28(4): 196-201.

90. Wiegand C, Hipler UC. A superabsorbent polimer-containing wound dressing efficiently sequesters MMPs and inhibits collagenase activity in vitro. J Mater Sci Mater Med. 2013;24(10):2473-2478.

91. Wiegand C, White RJ. Binding and inhibition of protease enzymes, including MMPs, by a superabsorbent dressing in vitro. J Wound Care. 2013;22(5):221-227.

92. Krejner A, Grzela T. Modulation of matrix metalloproteinases, MMP-2 and MMP-9, activity by hydrofiber-foam hybrid dressing - relevant support in a treatment of chronic wounds. Cent Eur J Immunol. 2015;40(3):391-394.

93. De Smet K, van den Plas D, Lens D, Sollie P. Pre-clinical evaluation of a new antimicrobial enzyme for the control of wound bioburden. Wounds. 2009;21(3):65-73.

94. Tauzin H, Humbert P, Viennet C, Saas P, Muret P. Human amniotic membrane in the management of chronic venous leg ulcers. Ann Dermatol Venereol. 2011;138(8-9):572-579.

95. Litwiniuk M, Grzela T. Amniotic membrane: new concepts for an old dressing. Wound Repair Regen. 2014;22(4):451-456.

96. Litwiniuk M, Bikowska B, Niderla-Bielińska J, et al. Potential role of metalloproteinase inhibitors from radiation-sterilized amnion dressings in the healing of venous leg ulcers. Mol Med Rep. 2012;6(4):723-728.

97. Litwiniuk M, Bikowska B, Niderla-Bielińska J, et al. High molecular weight hyaluronan and stroma-embedded factors of radiation-sterilized amniotic membrane stimulate proliferation of $\mathrm{HaCaT}$ cell line in vitro. Cent Eur J Immunol. 2011;36(4):205-211.

98. Diegelmann RF, Evans MC. Wound healing: an overview of acute, fibrotic and delayed healing. Front Biosci. 2004;9:283-289.

99. Gulino GR, Magnetto C, Khadjavi A, et al. Oxygen-loaded nanodroplets effectively abrogate hypoxia dysregulating effects on secretion of MMP-9 and TIMP-1 by human monocytes. Mediators Inflamm. 2015;2015:964838. 
100. Khadjavi A, Magnetto C, Panariti A, et al. Chitosan-shelled oxygenloaded nanodroplets abrogate hypoxia dysregulation of human keratinocyte gelatinases and inhibitors: new insights for chronic wound healing. Toxicol Appl Pharmacol. 2015;286(3):198-206.
101. Basilico N, Magnetto C, D’Alessandro S, et al. Dextran-shelled oxygen-loaded nanodroplets reestablish a normoxia-like pro-angiogenic phenotype and behavior in hypoxic human dermal microvascular endothelium. Toxicol Appl Pharmacol. 2015;288(3):330-338.

\section{Publish your work in this journal}

Chronic Wound Care Management and Research is an international, peer reviewed, open access, online journal publishing original research, reviews, editorials, and commentaries on the causes and management of chronic wounds and the major issues related to chronic wound management. Topics also include chronic wounds as comorbidities to other conditions, patient adherence to therapy, and the economic burden of chronic wounds. The manuscript management system is completely online and includes a very quick and fair peer review system, which is all easy to use. Visit http://www.dovepress.com/testimonials.php to read real quotes from published authors.

Submit your manuscript here: http://www.dovepress.com/chronic-wound-care-management-and-research-journal 